\title{
What caused the Seveso explosion?
}

SCIENTISTS investigating the disastrous accident which occurred at the Icmesa chemical plant in the Italian town of Séveso, on 10 July 1976 have so far failed to identify fully the cause of the explosion. This is the disturbing state of affairs at the end of two years of intensive research by chemists employed by Givaudan, the Swiss owners of Icmesa.

The accident happened in a reactor used for the production of trichlorophenol. Six and a half hours after the reactor had finished its run, an unexpected rise in temperature in the vessel resulted in a pressure increase sufficient to blow a safety valve on a vent pipe. In the ensuing discharge from the pipe was an extremely toxic byproduct of the reaction-2,3,7,8tetrachlorodibenzo-p-dioxin (dioxin)-and this was deposited over Séveso and its environs.

The scientist leading the investigation for Givaudan is the company's chief chemist, Dr J. Sambeth. He told Nature of the difficulties he had encountered in his attempts to identify the sequence of events which led up to the reactor's discharging of its contents. His frustration is all too apparent and, needless to say, understandable. It is Sambeth who has to help with the preparation of Givaudan's defence for the forthcoming trial in an Italian court, which will deal with the accident. In a hearing which is likely to become a legal test case, Sambeth intends to argue that the accident at Icmesa was neither foreseeable, nor the result of negligence.

It is the view of a large section of the chemical industry that Séveso should never have happened. The political damage which has been experienced by Givaudan and its Swiss parent company, F. Hoffmann La Roche, is not restricted to them alone. Many giants of the chemical industry feel that they, too, have suffered as a result. Far greater demands have been made on them recently to curb pollution in general.

Givaudan are sensitive to the suggestion made in Italy that the company operated in Séveso because of the Italian pollution laws, which are less vigorous than those in Switzerland. They are quick to deny the accusation. Their plant at Icmesa, they say, had to work within the Italian law. What of the charge that they skimped on investment in the plant? Sambeth claims that the reverse is the truth, claiming that not only has Givaudan poured millions of Swiss francs into the site, as part of a programme of modernisation, but that figures are available to prove it.

Against this background, it is hardly surprising that Givaudan are anxious to establish the causes of the accident. Sambeth reports that the company's scientists have concentrated their efforts on an attempt to reproduce the conditions in the trichlorophenol reactor on $10 \mathrm{July}$; as well as on a study of the operating procedure in use at Icmesa.

One of the questions which has been asked concerned the previous recorded accidents in reactors manufacturing trichlorophenol. Was Givaudan aware of them? Indeed they were, retorts Sambeth; claiming that it was this experience which governed both the design and operation of the Séveso plant. The reaction employed in the trichlorophenol reactor is the hydrolysis of tetrachlorobenzene to sodium trichlorophenate using sodium hydroxide. Dioxin is produced as an unwanted byproduct during the reaction. There is a choice between two solvents for the hydrolytic process-methanol or ethylene glycol. Givaudan chose the latter, for methanol would have had a pressure of 20 Atmospheres in the reactor, and any pressure vessel forms a hazard to workers. Although yields are better with methanol, the company decided against it in view of its implication in two accidents which occurred in Germany in 1953.

But ethylene glycol also has its hazards. In 1968, it was the solvent used in a trichlorophenol reactor at the site of Coalite and Chemical Products of Bolsover, which exploded, killing one engineer and contaminating a further seventy-nine employees with dioxin. The heating system at Coalite used oil in a primary circuit, which was often at a temperature close to $300{ }^{\circ} \mathrm{C}$. The optimum temperature for the reaction to produce trichlorophenate is about $180^{\circ} \mathrm{C}$. Above this temperature, the danger of an exothermic reaction starting is very real, particularly when the solvent has been removed.

The critical temperature is $230{ }^{\circ} \mathrm{C}$; and once the exothermic process has started, the temperature rises rapidly to about $410^{\circ} \mathrm{C}$. To avoid the danger of localised heating in their system, Givaudan used superheated steam, which they insist would never rise above $200{ }^{\circ} \mathrm{C}$. In addition, they could 'flush' cold water through these heating coils in a matter of minutes to reduce any unwanted temperature rise. To cope with the possible problem of blockages in the vessel pipes, Givaudan allowed xylene to circulate through the system. The vent pipe which discharged the reactor contents in 1976
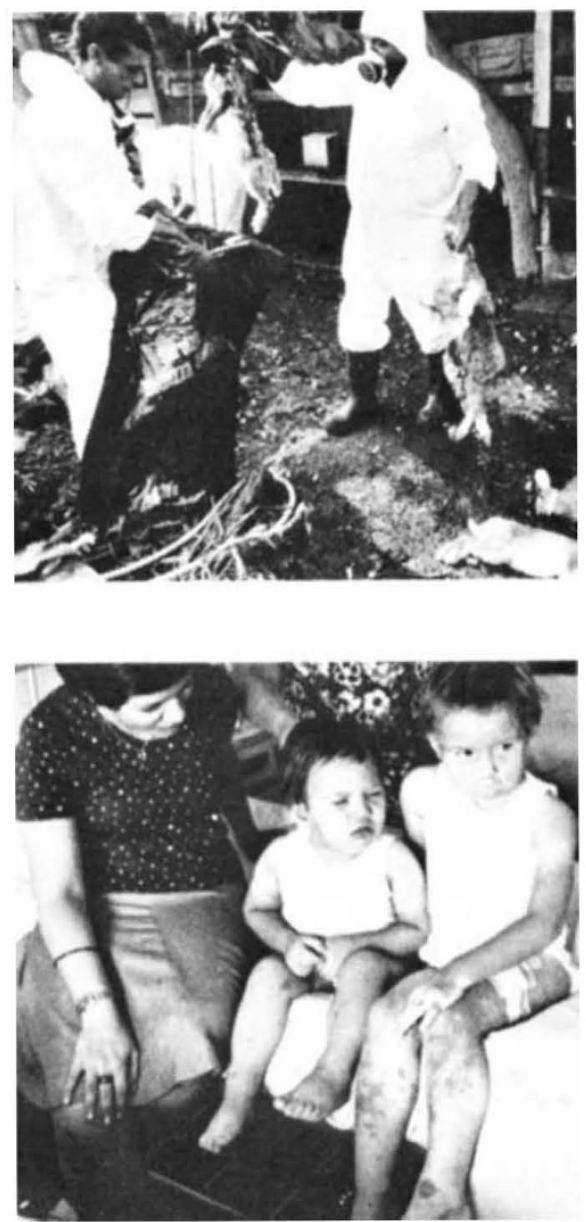

was set to do so at a pressure of 3.8 Atmospheres-the vapour pressure of xylene at $180^{\circ} \mathrm{C}$. According to Sambeth, this was an added safety factor, but one designed to cope with problems at the beginning of the reactor run and not at the end, which was when they occurred at Séveso.

Sambeth also states that the volume of the reactor solvent was also carefully controlled for safety reasons. Solvent is required to reduce the viscosity of the reaction mix, and it has been shown that conditions in the reactor become dangerous if the heat is retained after the solvent is removed. In view of this, Givaudan insist that only $50 \%$ of the solvent was removed after each run; and on the day in question, it was just $15 \%$. The final recorded temperature on 10 July was $158^{\circ} \mathrm{C}$.

Sambeth reports that chemists at Givaudan have attempted to simulate the reaction conditions with $15 \%$ of the solvent removed. However, in spite of their heating the mix to temperatures between $160{ }^{\circ} \mathrm{C}$ and $217^{\circ} \mathrm{C}$ for up to eight hours, they have been unable to start an exothermic reaction. Raising the temperature beyond this range, the chemists found a radical alteration in the properties of the mix. At $260{ }^{\circ} \mathrm{C}$, the $\mathrm{pH}$ of the mix changes from alkaline to acid, and the solution becomes an insoluble suspension. These 
changing conditions result in dechlorination of the trichlorophenate and an increasing concentration of dioxin.

The easiest and most reliable method of assessing the quantity of dioxin released during the Séveso accident would have been to examine the reactor contents in the wake of the explosion. This was never done. A court order prevented anyone from investigating the reactor contents for fourteen months; all estimates made by the Italian authorities had to be calculated from the concentration of the chemical on exposed surfaces at Séveso. The figure arrived at was 0.5 to $1.5 \mathrm{~kg}$. But the court order could have had more serious consequences. Sambeth believes that it is unlikely that the reactor contents would have changed a great deal in the intervening months between accident and investigation of the reactor; but he concedes that a change is not impossible, and that it could complicate his research programme.

Two further possibilities had also to be studied by Givaudan. The ethylene glycol solvent might have decomposed, generating large quantities of hydrogen; or air introduced into the vessel might have formed peroxides on the reaction surface. Neither of these changes was observed in the laboratory.
With most of the options ruled out, Sambeth is indeed puzzled as to the cause of the Séveso explosion. He says that other chemical companies have been approached for assistance, but none has managed as yet to provide a satisfactory explanation of the events on 10 July. It is Sambeth's belief, in view of his investigations and of the original design of the trichlorophenol reactor, that Givaudan would be correct in considering the accident to have been unforseen, and that the company was not guilty of negligence. It remains to be seen whether the court agrees with this.

Alastair Hay

\section{European Patent Office poses problems for microbiologists}

Microbiologists considering patenting a new microbiological process, microbially-produced end product or even a genetically-engineered microorganism, face a maze of patent regulations daunting enough to disccurage all but the most confident. In particular, the requirements of the newest arrival on the international patents scene, the European Patent Office, with regard to 'microbiological' patents, are being strongly opposed by prospective patentees.

The European Patent Office in Munich has been set up under the European Patent Convention to enable patent rights in all European countries to be gained by a single application instead of by separate applications to the national offices. However, prospective patentees, mainly from the pharmaceutical and chemical industries, object that the present Rule 28 of the Convention dealing with microorganisms does not provide sufficient protection for the patentee while the patent is under examination.

Under Rule 28 the applicant must deposit cultures of the microorganisms specified in the patent application (if the microorganism is "not generally available to the public") when the patent is filed. The deposit must be with an approved culture collection to which the public have access. Most national patent laws require deposition of a culture on the grounds that the 'invention' has not been sufficiently described if a culture is not available.

The objection to Rule 28 arises from the conditions, or lack of them, governing the release of the culture while the patent is being examined. As soon as the patent is first published, some 18 months after filing, the culture is available on request to any legally-entitled person who undertakes to use it for experimental purposes only. In some countries, including the USA and
Japan, cultures are not released, or are only released under certain conditions, until the patent is granted. The prospect of a potentially valuable culture falling into the hands of competitors at such an early stage in the application and without any compensation for subsequent commercial misuse, has alarmed the chemical and pharmaceutical industries which have formed an informal association-MICROPATto lobby the EPO for changes in the regulations.

At a recent meeting of industrial microbiologists and patent experts, S. Crespi, Patents Controller of the National Research and Development Corporation, urged participants to keep up the pressure for change. The EPO is at present "receptive" to representations for change, said Crespi. Since there is no obligation to file patents with the EPO rather than the national patent offices the EPO undoubtedly wishes to avoid a boycott by its potential customers.

MICROPAT wants to limit the availability of cultures for which patents have not yet been granted. They have suggested that for residents of the countries specified in the patent application, the culture would be available at the time of first publication (18 months after filing the application) provided there is compensation for any commercial misuse of the culture before the patent is finally granted, which can take several years.

The UK national law does give such retrospective rights. In countries where such protection is not available, the culture should not be released until the second publication (when the patent is granted), as in Japan and the USA. MICROPAT also wants access to cultures by non-residents of the countries covered by the application to be restricted. Their only access should be through an independent resident inter- mediary who would be able to carry out experiments and communicate the results to them.

The requirements of the EPO also pose problems for the culture collections themselves. For the purposes of the EPO an 'approved' collection is one with which the EPO has made a contract. As the regulations stand, an approved collection would then have no right to refuse a culture on the grounds that it was too dangerous or difficult to handle. This has led to no contracts yet being agreed between EPO and the British culture collections -notably the National Collection of Industrial Bacteria-who are at present negotiating with the EPO for such rights of refusal.

Who would bear legal responsibility in the case of accidental loss or damage to the cultures also worries the collections. This will have to be clarified before agreements are signed. Dr I. J. Bousfield drew a distinction between the case of the EPO and the requirements of the Budapest Convention, 1977 (not yet ratified). This provides for a single deposition in a recognised 'International Depository Authority' to be sufficient for a patent to be filed anywhere in the world. In this case however the legal responsibility rests squarely on the governments of the countries concerned.

The requirement to release the culture to any legally-entitled person also raises ethical problems for the culture collections if the organism in question is a potential pathogen, and they are aware that the person requesting it is not competent to deal with it. The National Type Culture Collection, which deals with medically important bacteria, is reluctantly facing the prospect of dealing with 'patentable' microorganisms for the first time, since the Health and Safety at Work Commission require that a culture of any 